Revista Complutense de Educación

ISSNe: 1988-2793

http://dx.doi.org/10.5209/RCED.55356

\title{
Escuelas libres de violencias machistas
}

Autoras: Kika Fumero, Marian Moreno Llaneza y Carmen Ruiz Repullo

Editorial: Edicions UIB.

Año de publicación: 2016

Número de páginas: 180

ISBN: 978-84-8384-341-3

El último libro publicado en la Colección Estudis de Violència de Gènere de la Universitat de les Illes Balears, que vio la luz a finales del año 2016, constituye una interesante obra teórico-práctica para analizar, prevenir y combatir diferentes formas de violencia, derivadas todas ellas del machismo, como son la violencia contra las mujeres, contra las personas homosexuales o las personas trans. En este sentido, se trata de un volumen con una especial vocación de intervención práctica, elaborado por tres docentes con amplia experiencia, que ofrecen diferentes claves para prevenir las agresiones y convertir los centros educativos en lugares de respeto y aprendizaje sin violencia.

La obra se divide, además de la introducción, las consideraciones finales y la bibliografía, en cinco capítulos que permiten, en primer lugar, acceder a una teoría básica sobre la coeducación, la desigualdad o la violencia, para más tarde proponer pautas y sugerencias de intervención, tanto en el aula como en el propio centro educativo. Estas propuestas, a las que se dedican los capítulos finales, hacen significativa una obra en la que también destaca una intersante sistematización de las violencias machistas, partiendo del hecho de que son siempre violencias estructurales pues forman "parte de la estructura cultural, política, económica, religiosa y social de nuestra sociedad" (p. 15).

Para las autoras, coeducar es la acción de equilibrar las diferencias pues reconocen que la totalidad del alumnado ha estado, y sigue estando, socializada a través de múltiples agentes que perpetúan la desigualdad tanto de género como de identidad sexual. Así, recogen su propia experiencia en las aulas a lo largo de los años, a través de la que han identificado algunos campos simbólicos en los que se hace necesario trabajar con el alumnado por el carácter diferencial que presentan entre chicas y chicos: el cuidado de otras personas, la asunción de riesgos, la afectividad, el liderazgo, la ideas sobre maternidad/paternidad, el valor de las aportaciones de hombres y mujeres o el modelo de familia y de opción sexual.

El primer capítulo recorre de forma sintética la cuestión de la violencia de género en la adolescencia: su definición y características específicas. Su punto de partida es la definición que provee la Ley Orgánica 1/2004, de 28 de diciembre, de Medidas de Protección Integral contra la Violencia de Género, atendiendo entonces a la violencia que se produce en las relaciones de noviazgo adolescente, violencia ejercida por los chicos contra las chicas. Estas agresiones, a tenor de los estudios más recientes, no ha hecho más que aumentar entre las personas de menos edad. En el epígrafe, las 
autoras identifican teóricamente varios problemas que interactúan con este tipo de violencia: la socialización sexista, la construcción social del ideal de amor romántico y el modelo de masculinidad hegemónico.

A continuación, el capítulo siguiente profundiza en este marco de interpretación para explicar el proceso de violencia de género, utilizando para ello el modelo teórico de la "Escalera cíclica de la violencia de género en la adolescencia" (p. 63). Tras explicar las tipologías en la que se pueden ordenar las diferentes formas de violencia, el modelo de la escalera permite visualizar simbólicamente cómo se va gestionando el control y las agresiones en las relaciones tóxicas, y cómo las chicas van perdiendo progresivamente la autoestima y también las redes de apoyo, lo que hace más complicado escapar del círculo.

El tercer capítulo de la obra se dedica a la relación entre machismo y homotransfobia, explicando en primer lugar conceptos esenciales que tienen que ver con las personas homosexuales pero también con las personas trans o las interesexuales. El vocabulario básico recorre conceptos que no siempre domina el profesorado, como la diferencia entre orientación sexual e identidad de género, o el concepto de intersexualidad. En su exposición téorica, estas líneas dedican algo de espacio a recordar la situación de opresión en la que vivían — hasta hace no tanto tiempo en Españalas personas con sexualidades o identidades de género disidentes. También recuerdan las autoras que estas identidades eran denominadas como enfermedades desde textos de alcance internacional, algunos vigentes en la actualidad.

Profundizando en lo anterior, el epígrafe subsiguiente ofrece un panorama probablemente menos conocidos por el público comun, relativo a la experiencia de la transexualidad, la intersexualidad o la identidad de género en el sistema educativo español. En este apartado comienza a ofrecerse un paradigma más práctico, con vocación de ayudar al profesorado a enfrentarse a la diversidad de las aulas. Para ello, además de exponer el marco normativo de referencia, introducen casos reales que las autoras han vivido en su trayectoria profesional y las fórmulas que aplicaron para resolver los conflictos.

El quinto capítulo es, directamente, un manual de intervención. Valioso por lo contemporáneo e inclusivo y bastante novedoso en la literatura especializada, se ofrecen aquí las estrategias principales a seguir para obtener una escuela libre de machismo.Y lo hacen, esencialmente, proponiendo la construcción de un instrumento estratégico en las escuelas: un Plan de Igualdad. Las autoras explican que se trata de un "guion que coordina las diferentes acciones que se quieren respecto a la coeducación” (p. 135), una estrategia de acción que permite llevar adelante las iniciativas para prevenir, detectar y eliminar las situaciones de violencia. El capítulo no sólo explica cómo hacer el Plan — de qué partes se compone, cuáles son los agentes que deben intervenir, etc. - sino que también se incluye un interesante compendio de prácticas a desarrollar en el aula y/o en el centro para llevar a cabo las acciones.

La coeducación hoy es, para Fumero, Moreno y Ruiz, el respeto a la diversidad, respeto que permite la convivencia pacífica entre diversas realidades que afectan tanto a las identidades como a las orientaciones sexuales (p. 166). Su texto es un volumen comprometido con la igualdad pero también con los cambios sociales que presentan múltiples y novedosos retos a una escuela que necesita adaptarse a ellos pero que no siempre cuenta con las herramientas necesarias. Escuelas libres de violencias machistas es una obra tremendamente útil para el profesorado, sencilla y sintética, que presenta los problemas que hoy existen en las aulas desde el punto de 
vista de género e identidad sexual pero que, no conformándose con el diagnóstico de esos problemas, sugiere prácticas de intervención y soluciones para conseguir una realidad más equilibrada, más justa y, sobre todo, libre de violencia.

El texto es una lectura muy recomendable para profesorado y personal directivo de centros de educación secundaria pero también tiene interés - por su mirada inclusiva y su puesta al día de diferentes problemáticas que existen hoy - para el resto de niveles educativos.

María Isabel Menéndez Menéndez

Universidad de Burgos mimenendez@ubu.es 